\title{
Sardinha, D. (2014). Orden y tiempo en la filosofía de Foucault (Trad. M.L. Pulido). Medellín: Editorial Universidad de Antioquia. ISBN: 978-958-714-627-1. Número de páginas: 236.
}

doi:10.11144/Javeriana.uph33-66.rotf

EL LIBRO ORDEN Y TIEMPO EN LA FILOSOFÍA DE FOUCAULT corresponde a la tesis doctoral en filosofía de Diogo Sardinha, escrita inicialmente en francés con el título: Ordre et temps dans la philosophie de Foucault (2011). Actualmente, Sardinha trabaja en el centro de filosofía de las ciencias de la Universidad de Lisboa, es presidente del Colegio Internacional de Filosofía en París y desarrolla su investigación en: "Violencia y política. El motín como forma de movimiento salvaje", Otros de sus trabajos son: L'Émancipation de Kant à Deleuze (2013), el dossier colectivo L'Homme après sa mort, Kant après Foucault (2012) y el libro Vivre en Europe: philosophie, politique et science aujourd'hui (2010). La traducción al español que reseñamos es de Martha Lucia Pulido Correa, doctora en ciencias literarias y humanas de la Universidad de París XII (Paris-Val-de-Marne), investigadora de la Universidad de Antioquia y profesora visitante en UFSC-PGET, Brasil.

En Orden y tiempo en la filosofia de Foucault, Sardinha nos propone una investigación de la sistematicidad que articula la arqueología del saber, la genealogía del poder y la ética en el pensamiento de Foucault. Esto lo realiza a partir de los conceptos de orden y tiempo, con los que atraviesa cada uno de los capítulos al modo de un pulso continuo, para indicar las relaciones que se desenvuelven entre el fondo y la superficie de la propuesta filosófica de Foucault. Una perspectiva de lectura que recuerda el método dialéctico -según las indicaciones de Étienne Balibar (p. 16) en el prefacio del libro- intentando estructurar el conflicto de temporalidades entre las disposiciones de saberes, los dispositivos de poder y las transformaciones de principios éticos para desembocar en una sistematicidad sin fin. Aún más, una interpretación intempestiva, deconstructora y polémica - como dice Alberto Castrillón (pp. 11-12) en el prefacio a la edición en español-, en cuanto torna las 
discontinuidades en puntos de enlace, buscando la coherencia de esta obra filosófica e, incluso, proponiendo su arquitectónica como un sistema de libertad.

De este modo, la investigación de Sardinha se divide en tres partes: la primera, La relación fundamental (pp. 35-90) tiene como foco las metamorfosis históricas y las relaciones fundamentales que se tejen entre arqueología, genealogía y ética. La segunda, El tiempo espacializado (pp. 91-164) se dedica a detallar la topología del pensamiento que traza las metamorfosis históricas, una mirada singular de los lugares, no-lugares y los lugares otros que configuran y reconfiguran las relaciones entre el saber, el poder y las resistencias. Y, la tercera, $L$ a singularidad de la ética y sus consecuencias (pp. 165-210) muestra la ética como plano articulador de las búsquedas arqueológicas y genealógicas, comprobando nuevamente su sistematicidad. Este largo y riguroso trayecto lo esbozamos enseguida.

La primera parte, La relación fundamental, inicia con el capítulo "Las palabras y las cosas: la reconducción de los saberes a sus condiciones de posibilidad” (pp. 37-48), su atención se centra en la arqueología en cuanto indagación sobre las condiciones de posibilidad del saber, cuya potencia analítica y crítica corresponde a la concepción de una historicidad no metafísica de este, es decir, a la pregunta por los acontecimientos arqueológicos como rupturas o discontinuidades que crean nuevas epistemes históricas que permiten la configuración de sistemas de positividades, disposiciones y órdenes de saber siempre en mutación. Indaga los campos de ordenamiento de los discursos, sus relaciones y sus series; no obstante, se trata de campos inestables donde siempre brotan nuevas fracturas, nuevas disyunciones o heterotopías discursivas, y donde siempre se repite la diferencia entre el acontecimiento y el saber.

Después, el capítulo 2, "Vigilar y Castigar y la voluntad de saber: la disolución del vínculo clásico entre los sujetos y el soberano" (pp. 49-60) se dedica a los dispositivos de poder disciplinarios, para lo cual relata la historia del alma y del cuerpo modernos a partir de los trabajos de Foucault sobre la genealogía de la prisión y del dispositivo de sexualidad. Así, establece el modo como los dispositivos articulan saberes y poderes, esto es, racionalidades y funcionamientos, que trazan una espiral de instrumentos y efectos. He ahí la microfísica del poder o la genealogía del individuo moderno y la serie de tecnologías políticas que gobiernan su alma y su cuerpo, dóciles y útiles en el umbral de la sociedad moderna. En el flujo de esta investigación, la genealogía emerge como red articuladora donde 
las lógicas de poder tocan el cuerpo, de modo que se concretiza e se imbrica en los intersticios más íntimos e ínfimos del más anónimo.

El capítulo 3, "El uso de los placeres y la inquietud de sí: la valoración de la ética en detrimento de la moral” (pp. 61-74) presenta la relación fundamental que acontece en la ética. Así, como las disposiciones de saber componen el fondo ordenador de los discursos y la superficie continua de sus funciones de verdad, los dispositivos funcionan, en paralelo, como fondos ordenadores de las técnicas de poder en su multiplicidad y propagación de la malla de la vida social; entonces, la ética compone un fondo de creación, desde el que desestabiliza la continuidad superficial de las conductas gobernadas por los códigos morales y políticos. Por tanto, la relación fundamental de la ética es aquella por la que el sujeto, más allá de las reglas de conducta, puede constituirse como productor de su acción. Entre las densas capas de leyes políticas, sociales y morales que recorren la historicidad del sujeto, la ética espacializa ese campo aún indeterminado y no formado de la relación consigo mismo; no en vano, la rigurosa trayectoria de Foucault a través de la ética antigua y de la moral cristiana desde la que traza la genealogía de las prácticas de sí mismo en occidente, lo llevaron a afirmar la singularidad de la ética como plano de los ejercicios siempre renovados de sí sobre sí mismo.

En consecuencia, el capítulo 4 "El fondo y el fundamento" (pp. 75-90), con el que termina esta primera parte, deja un importante aporte para la investigación propuesta sobre la sistematicidad de la filosofía de Foucault, ya que desde los fondos discontinuos que trazan los acontecimientos en devenir en la arqueología del saber, se pasa del movimiento lento y envolvente de la genealogía de los dispositivos de poder, hacia la superficie casi continua de la ética con sus variaciones intersticiales de las prácticas de libertad. No obstante, sobrevive la relación fundamental entre fondos ordenadores y superficies continuas, la cual indica las articulaciones entre las metamorfosis históricas.

Esta sistematicidad de la filosofía de Foucault se prolonga a través de los capítulos de la segunda parte El tiempo espacializado. En esta sección, indagando por las metamorfosis históricas, se arriba a una importante y aguda tesis sobre el modo como el tiempo se espacializa, sea a través de discursos, de dispositivos de poder o de prácticas de sujeción. Con algunas resonancias de Deleuze (1986: pp. 52-130), se afirma la topología de pensamiento que trazan los trabajos de Foucault. 
Esta sección se abre con el capítulo 5: "Las metamorfosis históricas" (pp. 93114), que indaga por el acontecimento arqueológico a partir de las relaciones que puede establecerse con los trabajos de Kant sobre la libertad como incondicional que condiciona su pensamiento ético; e, incluso, con las filosofías del acontecimiento, desde Nietzsche hasta Heidegger. Así, se destaca el carácter intempestivo, discontinuo y solitario del acontecimiento arqueológico que es, al mismo tiempo, condición de posibilidad de nuevas epistemes, disposiciones y órdenes de saber. Por tanto, la arqueología se torna una espacialidad de los acontecimientos discursivos llena de discontinuidades, rupturas radicales y fracturas intempestivas, fondo inestable del saber y, aún más, de sus funciones de verdad.

En el capítulo 6, "La historicidad y la visibilidad” (pp. 115-134), se prolonga esta espacialización de la temporalidad con el análisis de las relaciones entre saber y poder. En este punto, el flujo de la investigación se detiene en el concepto de campo y en los encadenamientos entre campos, pues a través de ellos se puede establecer las relaciones entre los discursos y los dispositivos de poder en la producción de campos de visibilidades e invisibilidades, en los juegos y distribuciones de luces y sombras tanto en los saberes como en las relaciones de poder. Pero, ¿cómo la conducta más anónima deja la sombra y vira objeto de saber y poder? ¿Qué relaciones se tejen entre campos de visibilidad y técnicas de poder? ¿Cómo un modo de vida puede ser menos gobernado? Una importante variación se indica: la diversidad entre la arqueología y la genealogía, pues de una a otra se pasa de las rupturas radicales entre epistemes a yuxtaposiciones, multiplicaciones y proliferación de diversas técnicas en un mismo dispositivo de poder. Así, de la espacialidad arqueológica discontinua y fracturada vamos a una espacialidad genealógica de multiplicidades de técnicas de poder entrelazadas, superponiendo épocas heterogéneas. No obstante, se pueden establecer importantes relaciones aún entre los discursos y la microfísica del poder, de manera que se generen, al mismo tiempo, nuevos espacios y nuevos sujetos: la producción de espacios de exclusión, de espacios reticulares o del panóptico indican, paralelamente, discursos normalizadores y prácticas de sujeción.

Después de este recorrido, el capítulo 7 "La espacialidad y la temporalidad" (pp. 135-164), con el que se cierra esta segunda parte, propone un análisis de la topología del pensamiento que se deriva de las articulaciones entre arqueología, genealogía y ética. Entre estas se ha esbozado la espacialidad de las metamorfosis 
históricas, las relaciones entre fondos y superficies de saberes, dispositivos de poder y modos de vida de los sujetos; aún más, los espacios de poder, los no- espacios y, sobre todo, los espacios otros de resistencias activas. De los espacios de encierro de poder, sea por la exclusión o del panóptico de las sociedades disciplinarias, se pasa a los espacios utópicos de rechazo reactivo al poder, paso que solo sirve de ideal trascendental, ya que hasta las heterotopías o los espacios otros de resistencias activas inmanentes a la malla de poder, crean un margen para el desvío, es decir, para los espacios éticos y políticos donde la vida trata de substraerse al poder para ser cada vez menos gobernada.

De esta constatación de la sistematicidad de la filosofía de Foucault a través de la espacialidad de las metamorfosis históricas, pasamos, entonces, a la tercera parte de la investigación, en la que prepondera la ética como plano de acción de sujetos y dominio articulador de las búsquedas arqueológica y genealógica. Consecuentemente, esa tercera parte se titula: Singularidad de la ética y sus consecuencias. El capítulo 8, "La ética de la sujeción a sí mismo" (pp. 169-184) señala el paso de la arqueología y la genealogía a la ética, esto es, el tránsito de dominios donde el sujeto es producto ya de epistemes históricas y discontinuas; ya de dispositivos y técnicas de poder heterogéneas, múltiples y reticulares en proliferación. Sin embargo, como indicase Deleuze (1986, pp. 101-130), entre estos estratos de saber y los diagramas de poder emerge la ética como pliegue donde el sujeto se produce como condición de sí mismo más allá de todo código moral o político; este pliegue efectúa la inversión del sujeto producido por saberes y poderes en la producción de sí mismo, aún con ecos kantianos, el autor la refiere como una constitución de sí por sí mismo.

Justamente, este movimiento lleva al capítulo 9, "La sistematicidad sin fin" (pp. 185-210), que cierra la tercera parte, donde la ética se propone como plano articulador de las búsquedas que atraviesan la arqueología y la genealogía. De modo que del sujeto sujetado entre las mallas discursivas, transdiscursivas y micropolíticas llegamos, finalmente, en este intersticio ético de los desvíos posibles y potenciales, a las prácticas de libertad, allí donde la vida aún queda como flujo no gobernable. Así, el recorrido por los saberes y poderes desemboca en esta ontología crítica de nosotros mismos para tornarnos sujetos de nosotros mismos. He ahí el argumento que permite volver a la tesis básica del libro sobre la sistematicidad de los trabajos de Foucault, justificando su valor y potencia para la filoso- 
fía contemporánea a partir de la experimentación de una sistematicidad libre. Más allá de los conceptos metafísicos tradicionales agotados de fundamento último, unidad, totalidad, organicidad e, incluso, de sistema, lo que se afirma es la sistematicidad entre los dominios del trabajo de Foucault que permitieron indicar los conceptos de orden y tiempo a través de la investigación.

Con ello, la conclusión del libro titulada "El sistema de libertad" (pp. 211-215) aclara la singularidad de este ordenamiento de los trabajos de Foucault, a partir de una nueva relación con los trabajos de Kant sobre el sujeto estético. Entonces, al modo del juego libre y espontáneo entre las facultades en la experiencia estética descrita por Kant, las relaciones entre el saber, el poder y la ética en los trabajos de Foucault trazan una serie de relaciones posibles, un juego abierto de series y articulaciones siempre en crecimiento e infinitas en el plano de la ética y la subjetividad. Esto le va a permitir al autor no solo reivindicar la importancia y actualidad de los trabajos de Foucault para la filosofía, sino indicar que esta sistematicidad libre es, incluso, una reinvención del concepto de sistema tan agotado en la vieja tradición metafísica.

Es evidente que Orden y tiempo en la filosofía de Foucault nos ofrece una investigación filosófica sistemática y rigurosa, cuya importancia está en los diversos elementos de análisis que renuevan las lecturas e interpretaciones de la filosofía de Foucault, tales como: las relaciones entre fondos y superficies que entrelazan la arqueología, la genealogía y la ética; la importancia de los conceptos como campo o encadenamiento de campos a partir de las relaciones entre saber y poder; la tesis de la espacialidad de las metamorfosis históricas configurando y reconfigurando espacialidades y visibilidades y, finalmente, la ética como plano articulador de arqueología y genealogía. Todo esto apuntó a establecer la sistematicidad de la filosofía de Foucault y, aún más, a indicar su renovación de la búsqueda de sistematicidad desviando la metafísica.

Sin embargo, queda por proponer una instigación crítica que trate acerca de la necesidad de desbordar la legitimación filosófica de los trabajos de Foucault en su sistematicidad y, a veces, los ecos kantianos en sus trabajos. La razón de ello es que desde otra perspectiva es posible apuntar al nomadismo de su propuesta filosófica, traduciendo la voluntad de desvío y deriva que siempre tuvieron las mutaciones en las búsquedas de Foucault: las diversas construcciones de las preguntas, las variaciones de los modos de problematizar, las redes múltiples y móviles de conceptos o 
los complejos cruzamientos entre planos transdiscursivos, dispositivos y prácticas de libertad anónimas y efímeras. Además, es necesario explorar el abordaje foucaultiano de las indagaciones arqueológicas y genealógicas que indican el azar que reverbera en las epistemes, funcionamientos de poder o modos de vida sedimentados; con el fin de afirmar siempre los excesos en sustracción: sea la locura, sea la conducta transgresora o esos extraños que siempre somos a nosotros mismos. De igual modo, debe hacerse con el nomadismo que lleva a pensar las heterotopías en saberes y poderes e, incluso, las prácticas de subjetivación apuntan a esa fuerza nómada de la vida desbordando cualquier sistema o sistematicidad. Desde esta perspectiva, el pulso continuo que se pasa entre escritura, pensamiento y movilización social en la filosofía de Foucault es la búsqueda de devenir siempre otros para ser cada vez menos gobernados; nomadismos y flujo de alteridad alteradora, tornando esta filosofía un cuidado de sí y una parrbésia tan necesarios para el pensamiento contemporáneo como para cualquier persona que aún busque en la filosofía un arte para vivir.

En suma, consideramos que Orden y tiempo en la filosofía de Foucault proporciona una mirada aguda y sistemática de la construcción de la filosofía de Foucault para un público abierto que quiera establecer articulaciones con sus saberes y prácticas locales. Para ello es indispensable que ese público tome de esta caja de herramientas lo que necesite para crear nuevos modos se saber, nuevas prácticas políticas y éticas tal como nos instigara Foucault.

Referencias

Deleuze, G. (1986). Foucault. Paris: Les éditions de Minuit.

Carolina Villada Castro Universidade Federal de Santa Catarina carolina.villadacastro@gmail.com 